\title{
Emergency Obstetric Care in Parakou: Availability in Maternity Hospitals, Knowledge, Attitudes and Practices of Providers
}

\section{Kabibou Salifou', Achille Awede A. Obossou'1, Idriss Olojuwole Alassane1, Imorou Rachidi Sidi1, Mahublo Vodouhe1, Fanny Hounkponou', Didier Komongui ${ }^{2}$, Rene-Xavier Perrin ${ }^{2}$}

${ }^{1}$ UFR of Gynecology and Obstetrics, Faculty of Medicine, University of Parakou, Parakou, Benin

${ }^{2}$ UFR of Gynecology and Obstetrics, Faculty of Health Sciences, University of Abomey-Calavi, Cotonou, Benin

Email: Salifoukabibou@yahoo.com

How to cite this paper: Salifou, K., Obossou, A.A.A., Alassane, I.O., Sidi, I.R., Vodouhe, M., Hounkponou, F., Komongui, D. and Perrin, R.-X. (2018) Emergency Obstetric Care in Parakou: Availability in Maternity Hospitals, Knowledge, Attitudes and Practices of Providers. Open Journal of Obstetrics and Gynecology, 8, 707-719. https://doi.org/10.4236/ojog.2018.88075

Received: June 6, 2018

Accepted: July 7, 2018

Published: July 10, 2018

Copyright $\odot 2018$ by authors and Scientific Research Publishing Inc. This work is licensed under the Creative Commons Attribution International License (CC BY 4.0).

http://creativecommons.org/licenses/by/4.0/

\section{(c) (i) Open Access}

\begin{abstract}
Objective: To evaluate the availability of emergency obstetric care (EmOC) in maternity hospitals in Parakou as well as the knowledge, attitudes and practices of EmOC providers in 2017. Material and method: This was a descriptive, cross-sectional analytical study conducted in the maternity wards of public and private health facilities in Parakou and the health care providers of the maternity wards. Epi Data software version 3.1, Epi Info version 7.2 and EXCEL 2007 were used for data processing. Results: A total of 17 maternity homes and 91 providers participated in the study. All 7 basic functions (BEmOC) were available in $23.53 \%$ of these maternities. Providers' knowledge of EmOC was good at $6.59 \%$, average at $15.38 \%$, insufficient at $24.18 \%$ and bad at $53.85 \%$. As for the attitudes, they were just in $3.30 \%$, approximate in $36.26 \%$, wrong in $26.37 \%$ and harmful in $34.07 \%$. Regarding the practices of these providers, they were adequate in $6.59 \%$, inadequate in $38.46 \%$ and harmful in $54.95 \%$. The global knowledge, attitudes and practices (CAP) score is acceptable in the majority of providers $(57.14 \%)$. It is poor in $38.46 \%$ and good in $4.40 \%$. Conclusion: In Parakou, the availability of emergency obstetric care (EmOC) contrasts with the level of knowledge, attitudes and practices of providers who require training in EmOC.
\end{abstract}

\section{Keywords}

Emergency Obstetric Care, Availability, Knowledge, Attitude, Practice

\section{Introduction}

Like all African countries, south of the Sahara, the major health challenge faced 
by Benin is the reduction of maternal mortality. Indeed, according to the global interagency group for the estimation of maternal mortality, Benin has 340 maternal deaths per 100,000 live births of which $75 \%$ is involved in health facilities [1]. In 2014, it revealed that out of 1000 children born in Benin, 67 would die before reaching their first birthday, and 115 before reaching their fifth birthday [2]. To accelerate the reduction of maternal mortality (RMM), the actions to be carried out have been oriented towards three axes namely: family planning, assisted delivery assisted by qualified personnel and Emergency Obstetric Care (EmOC) [2] [3]. These EmOCs are interventions immediately available 24 hours a day for all pregnant, parturient or childbirth and without them, they will be exposed to major complications that may lead to their death sooner or later. In the context of Millennium Development Goals (MDGs) 5 and 4, there was talk of reducing maternal mortality by $75 \%$ by the end of 2015 , which was to bring maternal mortality to 125 deaths per 100,000 live births for Benin [4]. But it is clear that this goal has not been achieved. One of the reasons for this failure is that about $61 \%$ of women in the world give birth in the presence of a skilled provider [5]. The survey of emergency obstetric care (EmOC) needs carried out in Benin between 2009-2010, revealed that Benin has 5 health facilities dispensing EmOC for 1.465.143 inhabitants, a national rate of childbirth attended by a staff rated 58.2\%, a very low EmOC need satisfied, 2.6\% [6] [7]. Since then, actions have been taken by the health authorities in Benin to improve the level of achievement of these indicators but often without taking into account the motivations of the actors responsible for implementing its strategies. However, there is evidence that the analysis of data on the knowledge, attitudes and practices (CAP) of health care providers in maternity hospitals provides strategic health actors with crucial information for better development of health programs that benefit people [8]; hence in this study, our objective is to assess the availability of emergency obstetric care (EmOC), as well as the knowledge, attitudes and practices of EmOC providers in Parakou.

\section{Material and Method}

The study took place in maternity hospitals, health centers and clinics, public or private parish of Parakou, the third city of Benin whose population is estimated at 255,478 inhabitants in 2017 . It was about a descriptive cross-sectional study for analytical purposes. The data collection took place over a period of 3 months from March 1 to June 12017.

Sampling: We conducted a comprehensive census of targets meeting the inclusion criteria. The study population consisted of maternity wards of public and private health facilities in Parakou commune, recognized by the Ministry of Health and, on the other hand, providers (nursing staff) of maternity wards.

\subsection{Inclusion Criteria}

Included in this study were all maternity wards of public or private health facili- 
ties, sending their statistics to the National Health Information and Management System (SNIGS) and providing care for obstetric emergencies; as well as all the qualified caregivers namely: gynecologists obstetricians, general practitioners with surgical capacity, midwives, nurses and anesthetists, assigned to the activities of emergency obstetric care, present on the sites on the days of investigation and who gave informed consent to participate in the study.

\subsection{Exclusion Criteria}

All maternity facilities that did not provide access to their data and/or had obstetric care providers who were not available were excluded; the same was true for all maternity health care workers who did not give their consent to participate in the study.

Criteria for non-inclusion: not included, maternity hospitals not providing care for obstetric emergencies. As well as the nursing staff of these maternities not assigned to emergency obstetric care activities.

\subsection{Judgment Criteria}

\subsubsection{The Availability of EmOC}

It was at this level the actual availability of 9 functions according to the level of the health pyramid:

- basic emergency obstetric care (B EmOC) with 7 functions:

- administration of parenteral antibiotics

- administration of uterotonics (oxytocin)

- administration of parenteral anticonvulsants (magnesium sulphate)

- anual extraction of the placenta (artificial delivery)

- uterine evacuation (intra uterine manual aspiration, curettage and curettage)

- vaginal delivery with instrumental assistance (vacuum suction cup, forceps)

- basic neonatal resuscitation

- Comprete emergency obstetric care (CEmOC) with 9 functions, the 7 (B EmOC) and 2 additional functions that are:

- surgical procedure (caesarean section)

- blood transfusion

They are available in maternity hospitals of reference hospitals of the 1st, 2nd and 3rd level.

\subsubsection{Knowledge, Attitudes and Practices (CAP) of Providers}

The evaluation grid was developed by reference to the model proposed by Essi et al. [9].

Thus, the assessment of the level of knowledge has been quantified and restituted in 4 levels (bad, insufficient, average and good).

- Less than $50 \%$ of correct answers $=$ Bad

- Less than $65 \%$ of correct answers $=$ Insufficient

- Less than $85 \%$ of correct answers = Average

- More than $85 \%$ of correct answers $=$ Good 
As far as attitude is concerned, the analysis grid focused on the qualification of verbatim. Four criteria (fair, approximate, wrong and harmful):

- Less than $50 \%$ of correct answers = harmful

- Less than $65 \%$ of correct answers = wrong

- Less than $85 \%$ of correct answers = approximate

- More than $85 \%$ of correct answers = just

The analysis of the practice was established in 3 levels: harmful, inadequate and adequate.

- Less than $50 \%$ of correct answers = harmful

- Less than $85 \%$ of correct answers = inadequate

- More than $85 \%$ of correct answers = adequate

A global CAP score based on an adaptation of the model proposed by Essi et al. [9] was calculated by averaging scores of knowledge, attitude and practice. Three criteria were used to assess the overall CAP score: Bad, acceptable and good:

- Average score $<50 \%=$ bad CAP score

- Average score $<85 \%=$ acceptable CAP score

- Average score $\geq 85 \%$ = good CAP score

\subsection{Data Collection}

Data collection took place over a 3-month period from March 1 to June 1, 2017. The collection technique was a face-to-face interviewer interview. Collection tools were standardized questionnaires on paper.

- A questionnaire addressed to the maternity ward staff, concerning the different qualifications of available human resources and the material resources required for the available and functional EO during the last three months.

- A questionnaire addressed to the managers of the health structures surveyed or to the persons in charge of the pharmacies or pharmacies of these structures, relating to the necessary medicines for the EMS available during the last 3 months starting from the data present on the sheets of stocks.

- A questionnaire for selected maternity staff on their EmOC knowledge, attitudes and practices.

A pretest of the questionnaire was conducted to readjust some questions if necessary.

\subsection{Variables}

Variables related to the availability of EmOC: This was the actual availability of EmOC functions during the last 3 months preceding the survey. A resource (or function) was considered available if it was operational or used in the last 3 months prior to the survey. This availability has been evaluated on

- Availability of B EmOC: type of health facility: hospital center and teaching hospital (CHU) and health center (CS), existence of human resources (midwife or nurse or general practitioner or gynecologist obstetrician), existence 
equipment necessary for the B EmOC (vacuum cup, curettage box, MVA kit, revision gloves, mucosal aspirator, mask and self-inflating balloon, heat lamp or other means of warming the newborn), the existence drugs and products (injectable antibiotics, uterotonics: oxytocin, misoprostol tablet or capsule or ergometrine, anticonvulsants: magnesium sulfate injection, diazepam injection).

- Availability of C EmOC: Type of hospital: (Hospital center and CHU), physical presence or 24-hour telephone contact of an obstetric surgeon ( cesarean section): Obstetrician Gynecologist or General Practitioner with Surgical Capability, the physical presence or 24-hour telephone contact of an agent trained in anesthesia, the existence of other human resources (midwife, nurse,), the existence of drugs (SOUB) and products (blood products, anesthesia and resuscitation products), the existence of guidelines for blood transfusion and diagnostic means for blood and rhesus grouping, the existence of equipment necessary for surgery, and anesthesia.

\subsection{Knowledge Variables}

Definition of EmOC, BEmOC, CEmOC, Components or Functions of EmOC, Obstetrical Complications, Neonatal Complications, Knowledge of Helping Babies Breathe (HBB), Awareness of APGAR Score, Knowledge of Apparent Death Status of Newborn.

\subsection{Attitudinal Variables}

The contribution and effectiveness of EmOC in promoting maternal health and reducing maternal-neonatal mortality the interest of the training workshops in the implementation of EmOC, the management of postpartum and post abortion hemorrhages in the BEmOC, health facilities, the management of obstructed deliveries in the $\mathrm{BEmOC}$, health facilities, the neonatal resuscitation through the HBB method, Blood transfusion and cesarean section

Practice-related variables: usual use of the partograph, use of therapeutic protocols, management of postpartum and post abortion hemorrhages in the BEmOC, health facilities, management of obstructed labor in the BEmOC health facilities, management Hypertensive syndromes of pregnancy, management of maternal sepsis, practice of blood transfusion, practice of caesarean section.

\subsection{Sociodemographic Data of EmOC Providers}

Age, sex, marital status, qualification of the providers, number of years of service, type of establishment.

\subsection{Data Processing and Analysis}

The data collection was done with the Epi Data version 3.1 software. The Epi Info version 7.2 software allowed statistical analysis of the data. The EXCEL 2007 software made it possible to organize the data into tables and graphs (pie 
chart and histogram). Quantitative variables were expressed on average with a standard deviation and qualitative variables as a simple percentage. The Chi2 Pearson or Fisher statistical test was used as appropriate for the comparison of qualitative data. The difference was considered statistically significant for a probability $\mathrm{p}<0.05$.

\subsection{Ethical Considerations}

We obtained the favorable opinion of the local ethics committee for biomedical research, as well as the authorizations of the administrative authorities in charge of health at the departmental level (departmental direction of health) and local. An information note on the study and an informed consent form were sent to the respondents. The questionnaires were filled in anonymity. All data that were collected during our work have been and will be used only for this study and will remain confidential.

Moreover, for this study the authors reassure that there is no conflict of interest.

\section{Results}

At the end of our survey, 17 maternities meeting the inclusion criteria were evaluated, including 10 public and seven (7) private. Among the public maternity hospitals, there were two (2) belonging to the teaching hospital (CHU) and eight (8) to the Health Centers. Private sector maternity hospitals included four (4) hospitals and three (3) health centers.

Ninety-one (91) providers took part in this study out of 96 eligible (94.79\%). Five (5) officers did not participate in the study due to absence at the investigators' crossings.

\subsection{Sociodemographic Characteristics of Providers}

The average age of the providers was $36.87 \pm 7.30$ years with extremes of 21 and 60 years. The most represented age group was 30 - 39 years old (49.45\%).

Female subjects were the most numerous; they accounted for $82.42 \%$ of the workforce, with a sex ratio of 0.21 . Almost half of the providers in the maternity homes surveyed were midwives (49.45\%). Average seniority was $10.14 \pm 7.56$ years with extremes of 1 to 30 years. The majority of service providers (80.22\%) worked in public hospitals and $46.15 \%$ worked in the 2 teaching hospitals (CHU) (Table 1).

\subsection{Availability of EmOC}

Basic obstetrical care (BEmOC) was available in $4 / 17$ maternity homes $(23.53 \%)$. Two out of eleven health centers (18.18\%) permanently offered all 7 BEmOC functions compared to $50 \%$ in hospital centers. In hospitals, the availability of CEmOC was effective in one (1) out of two (50\%) teaching hospital maternity compared to one (1) out of four (25\%) private hospital maternity. Thus the hos- 
pital availability of nine (9) CEmOC functions was two (2) out of six, or 33.33\%. The overall availability of basic functions in maternity wards was therefore $25.53 \%$.

The functions available in all maternity wards were: parenteral administration of antibiotics, anticonvulsants, uterotonic (oxytocin) and delivery. The obstetric vacuum for vaginal assisted deliveries and the intrauterine manual aspiration were available in $47.06 \%$ and $82.35 \%$, respectively. Material needed for basic neonatal resuscitation was available in $88.24 \%$ of the maternities surveyed. Caesarean section was performed in all hospitals (2 CHU and 4 hospitals). In contrast, blood transfusion was available in $50 \%$ of hospitals (Table 2).

Thus, for 255,478 inhabitants, the commune of Parakou had 4 maternities which offered the emergency obstetric care of which 2 providing complete emergency obstetric care.

This availability of EmOC does not match the level of knowledge, attitudes, and practices of EmOC providers.

Table 1. Distribution of providers according to socio-professional characteristics, type of establishment and seniority.

\begin{tabular}{|c|c|c|}
\hline & Effective & Frequency (\%) \\
\hline \multicolumn{3}{|c|}{ Age group (years) } \\
\hline$<30$ & 15 & 16.48 \\
\hline $30-39$ & 45 & 49.45 \\
\hline $40-49$ & 26 & 28.57 \\
\hline$\geq 50$ & 5 & 5.49 \\
\hline \multicolumn{3}{|c|}{ Sex } \\
\hline Male & 16 & 17.58 \\
\hline Female & 75 & 82.42 \\
\hline \multicolumn{3}{|c|}{ Socio Professional category } \\
\hline Obstetrician gynecologist & 8 & 8.79 \\
\hline General practitioner & 8 & 8.79 \\
\hline Midwife & 45 & 49.45 \\
\hline Nurse & 23 & 25.27 \\
\hline Anesthetist & 7 & 7.69 \\
\hline \multicolumn{3}{|c|}{ Type of health facility } \\
\hline Teaching hospital (CHU) & 42 & 46.15 \\
\hline Hospital & 14 & 15.38 \\
\hline health centers (CS) & 35 & 38.46 \\
\hline \multicolumn{3}{|c|}{ Seniority (years) } \\
\hline$<10$ & 43 & 47.25 \\
\hline$\geq 10$ & 48 & 52.75 \\
\hline Total & 91 & 100.00 \\
\hline
\end{tabular}


Table 2. Availability of EmOC functions according to the type of health facility and the Parakou maternity sector of activity surveyed in 2017 .

\begin{tabular}{|c|c|c|c|c|c|c|}
\hline & \multicolumn{3}{|c|}{ Type of health facility } & \multicolumn{2}{|l|}{ Sector } & \multirow[b]{2}{*}{$\begin{array}{c}\text { Total } \\
\text { N (\%) }\end{array}$} \\
\hline & CHU n (\%) & Hospital n (\%) & CS n (\%) & Public n (\%) & $\begin{array}{c}\text { Private } \\
\text { N (\%) }\end{array}$ & \\
\hline $\mathrm{PA}^{\star}$ of antibiotic & $2(100.0)$ & $4(100.0)$ & $11(100.0)$ & $10(100.0)$ & $7(100.0)$ & $17(100.0)$ \\
\hline $\mathrm{PA}^{*}$ of uterotonic & $2(100.0)$ & $4(100.0)$ & $11(100.0)$ & $10(100.0)$ & $7(100.0)$ & $17(100.0)$ \\
\hline $\mathrm{PA}^{*}$ of Antic. ${ }^{*}$ & $2(100.0)$ & $4(100.0)$ & $11(100.0)$ & $10(100.0)$ & $7(100.0)$ & $17(100.0)$ \\
\hline Artificial delivery & $2(100.0)$ & $4(100.0)$ & $11(100.0)$ & $10(100.0)$ & $7(100.00)$ & $17(100.0)$ \\
\hline Vacuum extractor & $1(50.00)$ & $2(50.00)$ & $5(45.45)$ & $5(50.00)$ & $3(42.86)$ & $8(47.06)$ \\
\hline $\mathrm{AMIU}^{*}$ & $2(100.0)$ & $3(75.00)$ & $9(64.29)$ & $9(90.00)$ & $5(71.43)$ & $14(82.35)$ \\
\hline Resuscitation $\mathrm{HBB}^{\star}$ & $2(100.0)$ & $4(100.0)$ & $9(81.82)$ & $10(100.0)$ & $5(71.43)$ & $15(88.24)$ \\
\hline caesarean section & $2(100.0)$ & $4(100.0)$ & - & $2(100.0)$ & $4(100.0)$ & $6(100.0)$ \\
\hline Blood transfusion & $2(100.0)$ & $1(25.00)$ & - & $2(100.0)$ & $1(25.00)$ & $3(50.00)$ \\
\hline
\end{tabular}

$\mathrm{PA}^{*}$ : Parenteral Administration, AMIU*: manual vacuum aspiration of the uterus, $\mathrm{HBB}^{*}$ : Help Baby Breathe, Antic*: Anticonvulsivant.

\subsection{Providers' Knowledge}

In $42.86 \%$ of providers, notions of EmOC were acquired during academic studies and $43.96 \%$ during continuing education or during EmOC recycling.

The majority of the maternity staff was able to correctly define the acronym EmOC (78.02\%). Regarding the functions of the BEmOC, 53.84\% could identify them against $48.35 \%$ for CEmOC. The most known signaling function of EmOC was the administration of uterotonics in $79.12 \%$ of cases. Thus, the knowledge of maternity hospital providers of EmOC functions was good at $6.59 \%$, average at $15.38 \%$, insufficient at $24.18 \%$ and bad at $53.85 \%$

\subsection{Provider Attitudes}

According to $63.74 \%$ of Emergency Obstetric Care (EmOC) agents are very effective at reducing maternal and neonatal mortality, only one provider $(1.10 \%)$ lives ineffective. For $91.21 \%$ of these providers, in the case of postpartum and post-abortion hemorrhages, the administration of uterotonics is mandatory. In terms of basic neonatal resuscitation through the Helping Babies to Breathe concept, 59.34\% of providers find this method effective. Overall, the attitudes of EmOC providers were just at $3.30 \%$, approximate at $36.26 \%$, wrong at $26.37 \%$ and harmful at $34.07 \%$.

\subsection{Provider Practices}

As a method of uterine evacuation, intrauterine manual aspiration and artificial delivery were performed by $68.9 \%$ of health care providers. The use of vacuum extractor in cases of prolonged delivery was reported by $31.87 \%$ of providers. In obstetrical surgery, $80 \%$ of providers report that hemostatic hysterectomy is necessary in case of failure of nonsurgical management of postpartum haemorr- 
hage (PPH)). In general, provider practices were adequate in $6.59 \%$ of cases, inadequate in $38.46 \%$ and harmful in $54.95 \%$ Cases. Overall, the attitudes and practices of EmOC providers (CAP Global Score) are acceptable for the majority of healthcare providers, $57.14 \%, 38.46 \%$ bad and $4.40 \%$ good.

\subsection{Factors Associated with Attitudinal and Practical Knowledge (Global CAP)}

The highest number of bad CAP scores was mostly observed among female officers $(42.67 \%)$ and the highest CAP scores were mostly found in physicians. In fact, good and acceptable CAP scores were mostly observed among CHU providers and there was almost no overall bad global CAP score among providers who received more than one training in EmOC (Table 3).

\section{Discussion}

Twenty-three point three-three percent (23.53\%) of the health facilities surveyed permanently offer the seven (7) functions of BEmOC. Our results confirm the national study of Hounkpatin and al. who found in 2013 that BEmOC were

Table 3. Distribution of providers by overall CAP score by sex, medical specialty, place of practice and training in EmOC.

\begin{tabular}{|c|c|c|c|c|c|c|c|c|}
\hline & \multicolumn{8}{|c|}{ Global CAP in EmOC } \\
\hline & \multirow{2}{*}{$\mathrm{N}^{*}$} & \multicolumn{2}{|c|}{ Good } & \multicolumn{2}{|c|}{ Acceptable } & \multicolumn{2}{|c|}{ Bad } & \multirow{2}{*}{ P-value } \\
\hline & & $\mathrm{n}^{* *}$ & $\%^{* * *}$ & $\mathrm{n}$ & $\%$ & $\mathrm{~N}$ & $\%$ & \\
\hline \multicolumn{9}{|l|}{ Sex } \\
\hline Male & 16 & 3 & 18.75 & 10 & 62.50 & 3 & 18.75 & \multirow[b]{2}{*}{0.0038} \\
\hline Female & 75 & 1 & 1.33 & 42 & 56.00 & 32 & 42.67 & \\
\hline \multicolumn{9}{|l|}{$\begin{array}{c}\text { Socio-professional } \\
\text { category }\end{array}$} \\
\hline obstetrician-gynecologist & 8 & 2 & 25 & 4 & 50 & 2 & 25 & \\
\hline General practitioner & 8 & 1 & 12.50 & 5 & 62.50 & 2 & 25 & \\
\hline Midwife & 45 & 1 & 2.22 & 30 & 66.67 & 14 & 31.11 & 0.0273 \\
\hline Nurse & 23 & 0 & 0.00 & 9 & 39.13 & 14 & 60.87 & \\
\hline Anesthésiste & 07 & 0 & 0.00 & 4 & 57.14 & 3 & 42.86 & \\
\hline \multicolumn{9}{|l|}{ Type of health facility } \\
\hline Teaching hospital (CHU) & 42 & 2 & 4.76 & 30 & 71.43 & 10 & 23.81 & \\
\hline Hospital & 14 & 1 & 7.14 & 2 & 14.29 & 11 & 78.57 & 0.0055 \\
\hline Health center (CS) & 35 & 1 & 2.86 & 20 & 57.14 & 14 & 20 & \\
\hline \multicolumn{9}{|l|}{ Training session } \\
\hline One & 27 & 0 & 0.00 & 19 & 70.37 & 8 & 29.63 & 0.0173 \\
\hline More & 13 & 3 & 23.08 & 9 & 69.23 & 1 & 7.69 & \\
\hline
\end{tabular}


available in $25.8 \%$ of Benin maternity clinics [10]. In Bangladesh in 2015 Sikder and al. found $21 \%$ availability for Basic Emergency Obstetric Care [11]. Of the maternity units permanently offering BEmOC in Parakou, 30\% were public and $14.29 \%$ private. Lower availability of BEmOC supply was observed in the Indian subcontinent in 2010 by Mony and al. who found $6.09 \%$ of BEmOC offer in private institutions and $2.7 \%$ of BEmOC offer in public institutions [12]. This difference in our results with those reported in Bangladesh and the Indian subcontinent can be explained by the prioritization of strategies; Benin has spent the last 15 years investing in emergency obstetric care. On the other hand, the public sector was the first target of training under the EmOC, so the availability of EmOC was better in public health facilities. Specifically, the functions of the BEmOC that were not available were those that required equipment whose use required special skills. These are intrauterine manual aspiration and Obstetric vacuum extaction. At this level, there is a management problem in our health facilities in Parakou. The first level of dysfunction in the management is the lack of maintenance. Sometimes there is not much to repair but lack of technician to put the equipment in good condition, the latter is simply abandoned. The second level of dysfunction lies in the renewal of medical-technical equipment which is not systematic despite thousands of dollars hoarded in the bank accounts of health facilities. It is as if the managers of these health facilities do not understand the relationship between the permanent availability of BEmOC and the reduction of maternal mortality. A better commitment on their part is necessary to remedy this situation. The third level of malfunction is the misuse of equipment that is often not maintained after use. It follows its disappearance or deterioration. All nine complete functions are available in $33.33 \%$ of the surveyed hospitals. This availability is similar to that reported by Gabrysch and al. in Zambia in 2011 [13] and higher than that reported by Ameh and al in Iraq with $26.3 \%$ [14]. This partial availability comes from the same reasons as those noted in the maternity hospitals offering the BEmOC. With 4 health facilities providing obstetric care 24 hours a day (two dispensing CEmOC and two 2 BEmOC), Parakou has the minimum required by Word Health Organization (WHO) [4], which indicates the commitment of the central health authorities to bring together emergency obstetric care of targets in Nigeria, in the health zone of Ibadan, the locality of Oluyole, which has about the same number of inhabitants as Parakou, does not have any structure permanently offering EmOC [15]. However, despite this greater availability compared to other African countries, the maternal mortality ratio is still high, hence the value of assessing the knowledge, attitudes and practices of providers regarding EmOC. Thus, it was found that only $6.59 \%$ of maternity surveyed providers have a good knowledge of EmOC. In Rwanda in 2011, 6.9\% of providers had a good knowledge of EmOC [16] against $0.71 \%$ and $28.9 \%$ in two Nigerian studies conducted respectively by Ijadunola et al. in 2010 and Ebuehi et al. in 2013 [10] [17]. This low rate of knowledge leads to a poor understanding of the issues and therefore to harmful attitudes and practices, as is the case with these providers surveyed in Parakou. 
Overall, the attitudes of maternity providers with regard to EmOC are mostly harmful and wrong. Our results at this level are the opposite of those of the Ebuehi and al urban survey in Nigeria in 2013 [10]. The basis of this weakness of the EmOC knowledge, attitudes and practices (CAP) noted in our study remains the lack of training of the providers as it appears in Table 3. Indeed the factors associated with knowledge attitudes and practices of the providers were on the one hand, the sex and the socio-professional category. In addition, the associations between overall CAP score, type of health facility and number of training received in EmOC was significant. When we analyze these associated factors more deeply, they are all related to the level of training. Indeed the only female provider who had a good CAP was a gynecologist. On the other hand, it was among physicians that good and acceptable CAP score rates were higher without losing sight of the fact that among those trained in EmOC and those in teaching hospitals there were $7.69 \%$ and $23.81 \%$ respectively bad CAP score.

\section{Conclusion}

The availability of EmOC is in line with WHO recommendations in Parakou. The main functions that are not often available are those that require special equipment and because of mismanagement coupled with a lack of commitment of health authorities at the local level. This availability contrasts with the low overall CAPs of providers in maternity wards in Parakou commune. This weakness of CAP is based on the lack of training both in academic courses and in the course of employment. To address this, it is appropriate to institutionalize EmOC training in all training schools for health providers in general and those who train maternity care providers in particular. This training should focus on the acquisition of skills related to the different functions.

\section{Limit of the Study}

The present study was interested in the availability of the EmOC as well as the CAP in relation with them. It has not addressed the issue of quality of benefits, which is an important element in reducing maternal mortality. This aspect deserves to be analyzed by subsequent studies.

\section{References}

[1] Tchaou, B.A., Hounkponou, N.F.M, Salifou, K., Zoumenou, E. and Chobli, M. (2015) Les urgences obstétricales à l'hôpital universitaire de Parakou au Bénin: aspects cliniques, thérapeutiques et évolutifs. European Scientific Journal, 11, 1857-1881.

[2] Sachs,J.D. and McArthur, J.W. (2005) The Millennium Project: A Plan for Meeting the Millennium Development. The Lancet, 365, 347-353.

https://doi.org/10.1016/S0140-6736(05)70201-4

[3] Freedman, L.P., Graham, W.J., Brazier, E., Smith, J.M., Ensor, T. and Fauveau, V. (2007) Practical Lessons from Global Safe Motherhood Initiatives: Time for a New Focus on Implementation. The Lancet, 370, 383-391. 
https://doi.org/10.1016/S0140-6736(07)61581-5

[4] Organisation mondiale de la santé (OMS), UNFPA, UNICEF, AMDD. (2009) Surveillance des soins obstétricaux d'urgence : manuel d'utilisation (en ligne). Genève, OMS, cité le 13 Décembre 2016. http://www.whqlibdoc.who.int/publications/2011/9789242547733_fre.pdf

[5] Crow, S., Utley, M., Costello, A. and Pagel, C. (2012) How Many Births in Sub-Saharan Africa and South Asia Will Not Be Attended by a Skilled Birth Attendant between 2011 and 2015? BMC Pregnancy Childbirth, 12, 4. https://doi.org/10.1186/1471-2393-12-4

[6] Ministère de la Santé du Bénin. (2011) Evaluation des besoins en soins obstétricaux et néonatals d’urgence au Bénin (en ligne). Ministère de la santé du Bénin, Cotonou. http://www.sante.gouv.bj/documents/DSME/Validation_SONU.pdf

[7] Direction de la santé familiale (MS) (2006) Document de Stratégie de Réduction de la Mortalité Maternelle et néonatale 2006-2015. (en ligne) http://www.sante.gouv.bj/documents/DSME/Document_Strategie_RMMN_Benin Ver_Finale_14_avril_2006.pdf

[8] World Health Organization (WHO), HTM, STB. (2008) Advocacy, Communication and Social Mobilization for TB Control: A Guide to Developing Knowledge, Attitude, and Practice Surveys. WHO, Geneva.

http://www.stoptb.org/assets/documents/resources/publications/acsm/t-advocacy.p df

[9] Essi, M.J. and Njoya, O. (2013) Enquête CAP en recherche médicale. Health Sciences, 14, 1-3.

[10] Ebuehi, O.M., Chinda, G.N., Sotunde, O.M. and Oyetoyan, S.A. (2013) Emergency Obstetric Care: Urban Versus Rural Comparison of Health Workers' Knowledge, Attitude and Practice in River State, Nigeria-Implications for Maternal Health Care in Rivers State. Clinical Medicine and Diagnostics, 3, 29-51.

[11] Sikder, S.S., Labrique, A.B., Ali, H., Hanif, A.A.M., Klemm, R.D.W. and Mehra, S. (2015) Availability of Emergency Obstetric Care (EmOC) among Public and Private Health Facilities in Rural Northwest Bangladesh. BMC Public Health, 15, 1-14. https://doi.org/10.1186/s12889-015-1405-2

[12] Mony, P.K., Krishnamurthy, J., Thomas, A., Sankar, K., Ramesh, B.M. and Moses, S. (2013) Availability and Distribution of Emergency Obstetric Care Services in Karnataka State, South India: Access and Equity Considerations. PLOS ONE, 8, 1-8. https://doi.org/10.1371/journal.pone.0064126

[13] Gabrysch, S., Simushi, V. and Campbell, O.M.R. (2011) Availability and Distribution of, and Geographic Access to Emergency Obstetric Care in Zambia. International Journal of Gynecology \& Obstetrics, 114, 174-179. https://doi.org/10.1016/j.ijgo.2011.05.007

[14] Ameh, C.A., Bishop, S., Kongnyuy, E., Grady, K. and Broek, N. (2011) Challenges to the Provision of Emergency Obstetric Care in Iraq. Maternal and Child Health Journal, 15, 4-11. https://doi.org/10.1007/s10995-009-0545-3

[15] Eniola, A.B., Adebiyi, A.O. and Fatiregun, A.A. (2015) An Assessment of Emergency Obstetric Care Services in Oyo State, Nigeria. Annals of Community Medicine and Practice, 1, 1009.

[16] Puri, R., Rulisa, S., Joharifard, S., Wilkinson, J., Kyamanywa, P. and Thielman, N. (2012) Knowledge, Attitudes, and Practices in Safe Motherhood Care among Obstetric Providers in Bugesera, Rwanda. International Journal of Gynecology \& Obstetrics, 116, 124-127. https://doi.org/10.1016/j.ijgo.2011.09.025 
[17] Ijadunola, K.T., Ijadunola, M.Y., Esimai, O.A. and Abiona, T.C. (2010) New Paradigm Old Thinking: The Case for Emergency Obstetric Care in the Prevention of Maternal Mortality in Nigeria. BMC Womens Health, 10, 6.

https://doi.org/10.1186/1472-6874-10-6 